\title{
Dacrioadenite bilateral causada pelo vírus Epstein-Barr: relato de caso
}

\author{
Epstein-Barr virus bilateral dacryoadenitis: case report
}

\author{
Bernardo Kaplan Moscovici ${ }^{1}$ \\ Ivana Lopes Romero ${ }^{2}$ \\ José Vital Filho ${ }^{3}$ \\ Simone Haber Duellberg' Von Faber Bison ${ }^{4}$
}

Trabalho realizado no Departamento de Oftalmologia da Irmandade da Santa Casa de Misericórdia de São Paulo São Paulo (SP) - Brasil.

${ }^{1}$ Estagiário da Seção de Doenças Externas e Córnea do Departamento de Oftalmologia da Santa Casa de Misericórida de São Paulo - São Paulo (SP) - Brasil.

${ }^{2}$ Estagiário da Seção de Oculoplástica do Departamento de Oftalmologia da Santa Casa de Misericórida de São Paulo - São Paulo (SP) - Brasil.

${ }^{3}$ Chefe da Seção de Órbita do Departamento de Oftalmologia da Santa Casa de Misericórida de São Paulo - São Paulo (SP) - Brasil.

${ }^{4}$ Professora Doutora e Chefe da Seção de Vias Lacrimais do Departamento de Oftalmologia da Santa Casa de Misericórida de São Paulo - São Paulo (SP) - Brasil.

Endereço para correspondência: Bernardo Kaplan Moscovici. Rua das Mangabeiras, 150 - Apto. 81 - São Paulo (SP) CEP 01233-010

E-mail: bernardokaplan@yahoo.com.br

Recebido para publicação em 17.04.2009

Aprovação em 15.10.2009

Nota Editorial: Depois de concluída a análise do artigo sob sigilo editorial e com a anuência da Dra. Mônica de C. Alves Paula sobre a divulgação de seu nome como revisora, agradecemos sua participação neste processo.

\section{RESUMO}

Os autores apresentam um caso raro de dacrioadenite aguda bilateral associada à mononucleose. Paciente do sexo feminino, 27 anos, tinha aumento agudo da glândula lacrimal, bilateral, com sinais flogísticos. As alterações tomográficas e laboratoriais confirmaram o diagnóstico e o tratamento com esteróide sistêmico foi introduzido, com resolução completa dos sinais e sintomas. Comentários: A dacrioadenite é uma apresentação incomum da mononucleose infecciosa e pode minimizar outras manifestações desta doença. O diagnóstico de mononucleose deve ser considerado em casos de dacrioadenite aguda bilateral. Os esteróides sistêmicos contribuem para a resolução do quadro inflamatório.

Descritores: Dacriocistite/etiologia; Mononucleose infecciosa; Infecções por vírus EpsteinBarr; Dexametasona/uso terapêutico; Adulto; Feminino; Relatos de casos

\section{INTRODUÇÃO}

A dacrioadenite aguda é caracterizada por aumento e inflamação da glândula lacrimal, produzindo rubor, dor e edema na região súpero-lateral da pálpebra, causando uma característica ptose em "S". O quadro pode estar associado à diminuição da produção lacrimal reflexa, sintomas sistêmicos, acometimento de linfonodos e das glândulas salivares. Existem diferentes agentes etiológicos, sendo os virais os mais frequentes ${ }^{(1-5)}$.

A associação entre inflamação da glândula lacrimal e infecção pelo vírus Epstein-Barr (EBV), agente da mononucleose infecciosa, foi feita pela primeira vez na década de 50. A dacrioadenite pode ser, junto com a linfoadenopatia, o único sinal dessa doença ${ }^{(1)}$.

O EBV infecta de $80-98 \%$ da população adulta, em países industrializados aproximadamente um terço dos casos ocorre durante a adolescência e início da vida adulta ${ }^{(6-7)}$.

Outros relatos e séries de casos reforçam a importância do EBV como agente etiológico nos quadros agudos de dacrioadenite, principalmente em jovens e adolescentes ${ }^{(2-4)}$, sendo que a incidência estimada de dacrioadenite aguda por esse agente é de aproximadamente um caso por um milhão de pessoas por ano ${ }^{(2)}$.

Na tomografia computadorizada (TC) de órbita, observa-se aumento da glândula lacrimal, moldando o bulbo ocular, sem comprometimento ósseo ${ }^{(3,5)}$. Pode-se encontrar elevação da amilase sérica, além de alterações na velocidade de hemossedimentação (VHS) e hemograma, principalmente nos quadros agudos da mononucleose infecciosa.

Os autores relatam um caso de dacrioadenite aguda bilateral pelo EBV em uma paciente jovem e discutem exames diagnósticos, além de opções terapêuticas. 


\section{RELATO DO CASO}

G.S.L, 27 anos procurou o serviço oftalmológico de emergência da Santa Casa de Misericórida de São Paulo com queixa de tumoração periorbital bilateral com início progressivo e insidioso há um mês.

O quadro iniciou-se com edema e rubor nas pálpebras superiores, primeiramente à direita. Negava baixa acuidade visual referindo apenas dor à palpação. Negava febre ou queixas sistêmicas.

Ao exame, não apresentava alterações dos reflexos fotomotor e vermelho, motilidade ocular extrínseca, biomicroscopia, tonometria, fundoscopia e acuidade visual. Notava-se apenas edema mole das pálpebras superiores na região nasal e endurecido na região temporal (topografia de glândula lacrimal), gânglios submandibulares palpáveis e aumento discreto da glândula parótida (Figura 1).

Foram realizados exames sanguíneos, incluindo sorologias virais, amilase sérica, PPD, cálcio urinário e hemograma, sendo encontrado aumento do VHS e sorologia ELISA para EpsteinBarr IgM positiva.

A TC de órbita evidenciou aumento da glândula lacrimal bilateralmente, sendo feito o diagnóstico de dacrioadenite bilateral por Epstein-Barr (Figura 2).

Foi introduzido $10 \mathrm{mg}$ de dexametasona via endovenosa (dose de ataque) e manutenção com $4 \mathrm{mg}$ via endovenosa, $6 / 6 \mathrm{~h}$ por 5 dias. Ocorreu regressão do quadro em sete dias.

\section{DISCUSS ÃO}

A dacrioadenite causada pelo EBV é uma condição pouco diagnosticada em nosso meio, provavelmente por se tratar de uma doença autolimitada ${ }^{(1-2,6)}$.

O diagnóstico baseia-se em aspectos clínicos e exames complementares, sendo o quadro bacteriano, geralmente, agudo. Formas idiopáticas, neoplasias ou pseudotumores costumam ser unilaterais, com maior restrição de motilidade ocular e proptose, enquanto que as etiologias virais são mais frequentemente bilaterais e apresentam acometimento de linfonodos, como em nosso caso ${ }^{(1)}$.

O hemograma costuma trazer mais informações sugestivas do diagnóstico como linfocitose (presente em 70\% dos casos) que tem pico na segunda e terceira semana além de linfócitos atípicos e neutropenia relativa serem muito comuns. Nenhuma alteração foi encontrada no hemograma da nossa paciente. Outras alterações sugestivas são os exames de função hepática ${ }^{(6)}$.

Os demais exames sanguíneos podem incluir a busca de anticorpos heterófilos ou específicos, em nosso caso optamos por anticorpos específicos devido à história de mais de um mês de evolução, pois o teste de anticorpos heterófilos, primeiramente descrito por Paul e Bunnell está presente em 90\% dos pacientes nas primeiras duas semanas de evolução. Hoje, o teste de anticorpos heterófilos mais utilizado é o Monospot ${ }^{(6)}$.

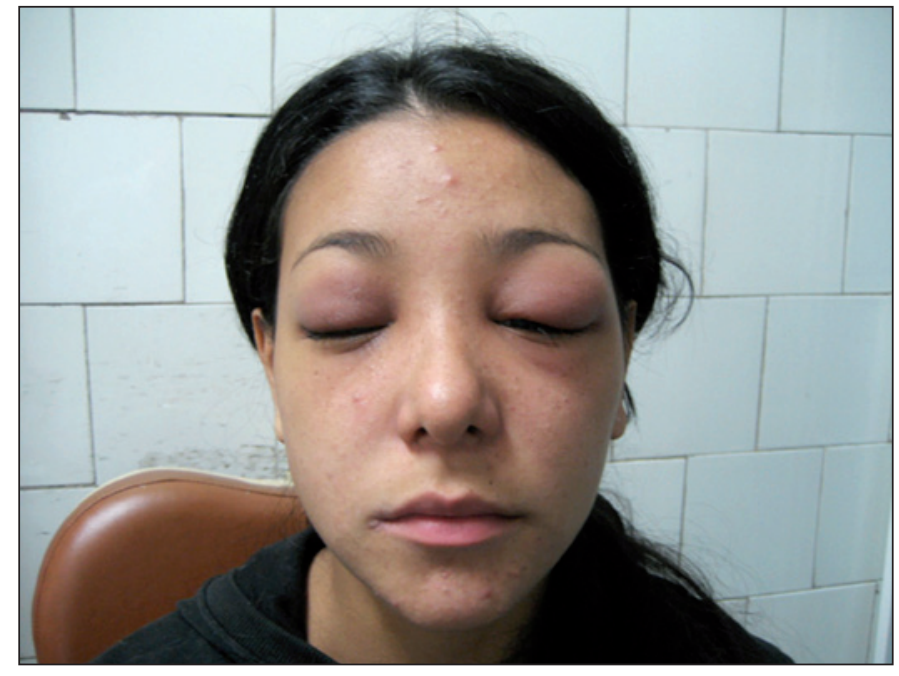

Figura 1 - Fotografia do edema palpebral e da ptose em "S"

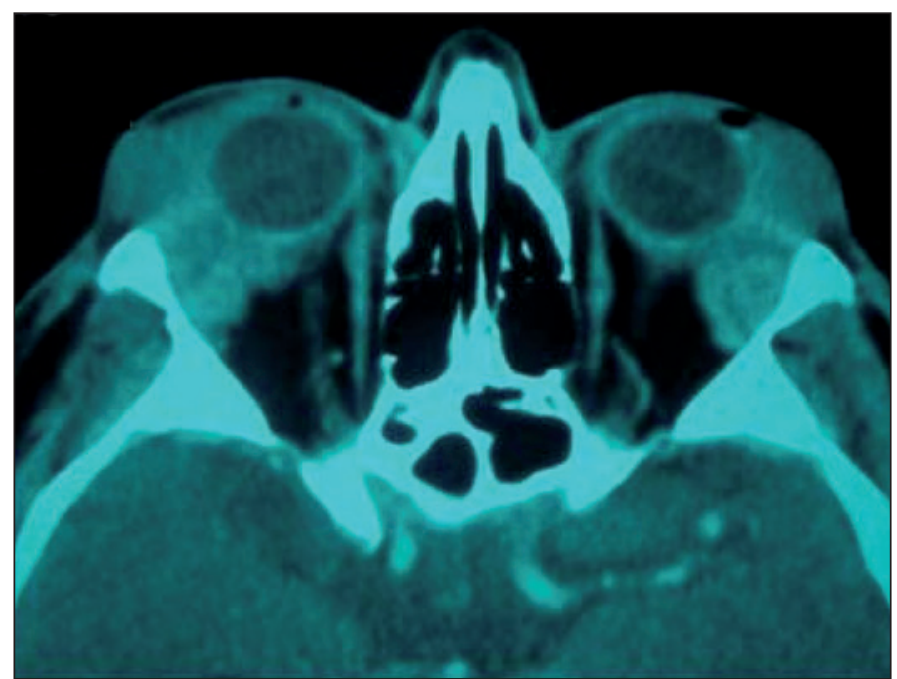

Figura 2 - Tomografia de órbita evidenciou aumento da glândula lacrimal bilateralmente, com limites imprecisos, respeitando bulbo ocular e paredes ósseas

Os anticorpos específicos se tornam detectáveis após seis semanas da infecção, e o primeiro a se elevar é o $\operatorname{IgM}$, que decresce em algumas semanas, enquanto o IgG começa a se elevar e persiste indefinidamente. Nossa paciente apresentou alteração no IgM. A presença de anticorpos para antígenos virais capsídeos e ausência de aumento de anticorpos contra antígenos virais nucleares é diagnóstico de infecção recente para $\mathrm{EBV}^{(1)}$.

A TC de órbita é o exame de imagem mais utilizado e evidencia aumento local da glândula lacrimal, sem comprometimento ósseo, como visto em nosso caso ${ }^{(2)}$.

Apesar de todos esses testes diagnósticos, muitos autores questionam tal diagnóstico sorológico sem a identificação viral ou detecção do antígeno ácido nucléico na glândula lacrimal ou na conjuntiva ${ }^{(1)}$. 
Em casos refratários à terapia, pode ser necessária biópsia local, com o objetivo de descartar outras etiologias, como brucelose e sarcoidose. Caracteriza-se o quadro como idiopático quando outras etiologias forem excluídas ${ }^{(2)}$.

O tratamento para a dacrioadenite causada pelo EBV é realizado com agentes anti-inflamatórios, esteroidais ou não-esteroidais, visto que a infecção é autolimitada. Utiliza-se dexametasona ou metilpredinisolona intravenosa ou prednisona oral. Em casos refratários ao tratamento, pode-se utilizar injeções intralesionais de corticóide. Pode-se ainda utilizar agentes antivirais associados como o aciclovir, no entanto cinco ensaios clínicos não mostraram benefício clínico quando utilizado isoladamente ${ }^{(1-4,8-10)}$.

Alguns casos podem evoluir com complicações como síndrome de Sjögren, e não há evidências na literatura se a terapia pode prevenir tais complicações ${ }^{(2)}$. Nossa paciente que foi sujeita à terapia com corticóides apresentou melhora do quadro, sem evidências de complicações até o momento.

\section{ABSTRACT}

The authors present a rare case of acute bilateral dacryoadenitis in association with infectious mononucleosis. A 27 yearold woman had acute bilateral lacrimal gland enlargement with inflammatory signs. The CT scan findings and laboratorial investigations confirmed the diagnosis of infectious mononucleosis. The systemic treatment with intravenous steroids was initiated leading to complete remission of the signs and symptoms. Comments: Dacryoadenitis is an uncommon mani- festation of infectious mononucleosis and may minimize other signs of the disease. Mononucleosis has to be considered in acute dacryoadenitis cases. Systemic steroids contribute to the fast regression of inflammatory condition.

Keywords: Dacryocystitis/etiology; Infectious mononucleosis; Epstein-Barr virus infections; Dexamethasone/therapeutic use; Adult; Female; Case reports

\section{REFERÊNCIAS}

1. Tanner OR. Ocular manifestations of infections mononucleosis. Arch Ophthalmol. 1954;51:229-41.

2. Rhem MN, Wilhelmus KR, Jones DB. Epstein-Barr virus dacryoadenitis. Am J Ophthalmol. 2000;129(3):372-5.

3. Marchese-Ragona R, Marioni G, Staffieri A, Filippis C. Acute infectious mononucleosis presenting with dacryoadenitis and tonsillitis. Acta Ophthalmol Scand. 2002;80(3):345-6.

4. Aburn NS, Sullivan TJ. Infectious mononucleosis presenting with dacryoadenitis. Ophthlmology. 1996;103(5):776-8.

5. Rootman J, Robertson W, Lapointe JS. Inflamatory diseases. In: Rootman J, editor. Diseases of the orbit. Philadelphia: Lippincott; 1988. p.159-75.

6. Costa IC, Vallada MG Mononucleose infecciosa. In: Focaccia R, Veronesi R. Tratado de Infectologia - Veronesi. Uberlândia; Atheneu; 2005. p.575-9.

7. Jenson HB. Acute complications of Epstein Barr virus infectious mononucleosis. Curr Opin Pediatr. 2000;12(3):263-8.

8. Pagano JS, Sixbey JW, Lin JC. Acyclovir and Epstein Barr virus infection. J Antimicrob Chemother. 1983;12(Suppl B):113-21.

9. Andersson J, Britton S, Ernberg I, Andersson U, Henle W. Sköldenberg B, et al. Effect of acyclovir on infectious mononucleosis: a double blind, placebocontrolled study. J Infect Dis. 1986;153(2):283-90.

10. Andersson J, Skoldenberg B, Henle W, Giesecke J, Ortgvist A, Julander I, et al. Acyclovir treatment in infectious mononucleosis: a clinical and virological study. Infection. 1987;15(Suppl 1):S14-20. 